\title{
As crónicas breves de um tempo
}

\section{Maria Helena Serôdio}

Em tempos que já lá vão - uns bons 410 anos - e em escrita inspirada, William Shakespeare designou um papel cultural para os actores: eles são, pela voz de Hamlet, "os modelos e as breves crónicas do tempo", razão pela qual aconselhava Polónio a recebê-los e instalá-los bem, até porque, advertia o príncipe, "antes tenhas um mau epitáfio depois de morto do que seres acusado por eles enquanto vives" (Hamlet, II, 2, 527).

Hoje há outras razões a justificarem o respeito pelos actores e por todos os que colaboram nessa arte colectiva de "desdobrar" - em cena e perante o público - esse mapa simbólico que o espectáculo de teatro oferece. E de o fazerem de uma forma muitas vezes inspirada, emotiva ou de inquieta interrogação posta à vida e ao mundo. Mas para afirmar ou negar esta evidência é necessário ir ao teatro e reflectir sobre a significação e valor de cada espectáculo que vemos.

É evidente que nem todos os que hoje escrevem para os jornais vão ao teatro, leram Shakespeare ou se interessam verdadeiramente por coisas da cultura. Terão o seu nicho de interesse e saber, como é óbvio, mas alguns deles, desastradamente, gostam ainda assim de falar - mal - de tudo, requintando-se sobretudo na maledicência quando se trata de teatro. Recordemos que foi, no passado, a Igreja - católica, mas, sobretudo, a protestante - a invectivar o teatro, será depois a censura política ou os interesses filisteus, e muitas vezes é simplesmente a incultura, o desinteresse ou os preconceitos sociais e culturais a fazê-lo.

Recordo, aliás, um crítico francês dos finais do séc. XIX - Francisque Sarcey - que, já velhinho e retido em casa por razões de (falta de) saúde, continuava a publicar indefectivelmente críticas aos espectáculos que se iam estreando. E quando instado a responder como era possivel fazê-lo (imaginamos a indignação de quem assim o interpelava...), respondeu serenamente: conhecia bem as peças (ou poderia sempre lê-las na quietude da sua casa), conhecia bem os actores e encenadores, pelo que não era dificil imaginar como se sairiam em cena, e acima de tudo, a situação trazia-Ihe uma vantagem acrescida: não se deixaria influenciar pelo espectáculo.
Deve ser, então, por razões tão sérias quanto estas, que alguns comentadores politicos portugueses se desunham a escrever contra o teatro, vendo nele uma "arte" menor, acarretando ainda por cima um desperdício inadmissivel de recursos públicos. E é curioso verificar que alguns dos que assim o invectivam - sem conhecimento real ou enquanto prisioneiros de uma imagem falsificada por azedumes e ressentimentos pessoais - até têm formação académica, são professores, e certamente rejeitariam trabalhos de alunos que escrevessem sobre o que não terão lido, visto ou estudado.

Em tempos de graves dificuldades económicas, em que a palavra de ordem que nos impõem é a de "recapitalizar os bancos" (depois do esbulho de alguns banqueiros inescrupulosos - descendentes por certo do "homem de sucesso" que o cavaquismo incensou - e da "natural" insensatez do sistema económico que nos desgoverna), um argumento que desqualifique o teatro e a cultura serve bem esse propósito. E entre a imposição governativa e a displicência jornalista, percebem-se as dificuldades insanáveis com que se debateria um director artístico do Teatro Nacional D. Maria II que, com uma programação definida e entregue atempadamente, vê reduzidas as verbas para quase metade. 0 final abrupto, que o actual Secretário de Estado da Cultura impôs à direcção que Diogo Infante assegurava nesse Teatro Nacional, não deixa de ser lamentável, tendo em conta a qualidade do trabalho que a todos os níveis aí se desenvolveu: na criação de espectáculos - de que o recente Amadeus foi prova eloquente -, na reorganização exemplar do Arquivo, na publicação atempada - e com grande qualidade de tradução e edição - dos textos dramáticos representados, na organização de cursos e de muitas outras iniciativas culturais e artísticas, num dinamismo generalizado da sua actuação a todos os níveis, enfim, numa rigorosa e inatacável gestão financeira.

Ora, neste tempo insensato e triste, prosseguir com a publicação da Sinais de cena só pode resultar de uma obstinação e boa vontade de todos os que, muito generosamente (e é em sentido bem literal), integram esta 
revista e a quem não posso deixar de agradecer: aos autores (e tradutores) que aqui colaboram, a quem aceitou generosamente publicitar aqui a sua actividade, aos que - nas companhias de teatro, no Museu Nacional do Teatro e noutras instituições - ajudaram a reunir materiais iconográficos, a esclarecer dúvidas ou, de um modo geral, a apoiar este trabalho.

Neste número, uma vez mais se cumprem as dez rubricas que assinalam, desde o primeiro número, a vontade de interrogar o teatro sob diversos pontos de vista, assinalando perspectivas, valências e resultados artísticos que não deixam de documentar também razões sociais e culturais mais vastas.

Assim, de três formas se interpela aqui o teatro inscrito na História: no "Arquivo solto", o Arquitecto Luís Soares Carneiro dá-nos, de forma competente, o histórico da construção do Teatro Nacional São João no Porto; em "Leituras", Ana Isabel Vasconcelos recenseia, com rigor, a documentação que um catálogo do Museu Nacional do Teatro oferece sobre o teatro e a República (e que acompanhava a exposição que José Carlos Alvarez aí promovera); e, nos "Passos em volta", David Luis Casimiro escreve, de modo informado e entusiástico, sobre a curiosa revisitação popular a um Auto da criação que a localidade de Urrós, em Trás-os-Montes, encenou de forma inspirada e muito participativa no passado mês de Setembro, e que se espera que seja remontada - sem os burricos, todavia - na Reitoria da Universidade de Lisboa no próximo mês de Janeiro.

No "Dossiê temático" são interrogadas as relações cada vez mais aliciantes para cientistas e gente de teatro - entre a ciência e o teatro pela escrita de um cientista que é também dramaturgo como é o caso de Carl Djerassi, mas também por reconhecidos estudiosos como Eva-Sabine Zehelein ou Mário Montenegro. E em "Leituras" assinalase, num artigo de Filomena Louro, a publicação de um livro sobre os estudos do "género, cultura visual e performance", que problematizam a questão do feminino, e que surge com a chancela do Centro de Estudos Humanísticos, da Universidade do Minho, e das edições Húmus.
Outras valências do teatro são ainda examinadas: as razões sociais que a rubrica "Em rede" assinala pela escrita de Isabel Aleixo, e, em "Estudos aplicados", podemos ler: a declaração de uma estética própria que António Branco identifica no seu artigo sobre o "teatro pobre", a elaboração teórica que Inês Lago tece em torno de Deleuze e Carmelo Bene, e a ponderação filosófica que Arthur E.A. Belloni desenvolve a propósito do sujeito no teatro contemporâneo.

Sobre o teatro que se vai fazendo em Itália surge aqui em "Notícias de fora" uma excelente recensão ao festival "Teatro a Corte" por Rita Martins, e em "Passos em volta" é Sebastiana Fadda que nos dá uma notável apreciação dos espectáculos que, vindos de Itália, se apresentaram no Festival Escrita na Paisagem que José Alberto Ferreira, de forma entusiástica, vem organizando e dirigindo há alguns anos em Évora. Pelo Porto, integrado no festival Odisseia, passaram algumas produções estrangeiras, em torno das quais Alexandra Moreira da Silva e Constança Carvalho Homem dinamizaram um "Seminário de novos críticos" (no âmbito do trabalho da Associação Portuguesa de Criticos de Teatro) e de que resultaram algumas linhas de reflexão em torno do coreógrafo Josef Nadj (Os corvos), da Schaubühne - em co-produção com um teatro de Telavive e do Ruhr - a propósito da Terceira geração, e de uma Medeia que Martinelli levou a Miragaia com actrizes africanas.

Outras análises em "Passos em volta" desenham uma boa cartografia do que o teatro em Portugal nos vai oferecendo em importantes gestos artísticos e culturais: Christine Zurbach visita o imaginário de João Paulo Seara Cardoso através de um espectáculo do Teatro das Marionetas do Porto, Emilia Costa interroga a proposta teatral de Jean Genet na recriação de Ela pelo Teatro da Cornucópia, e Francesca Rayner assinala uma oportuna interrogação política posta em cena por Ana Borralho e João Galante no Teatro Maria Matos.

Num ano em que nos deixaram para sempre a actriz Linda Silva, o cenógrafo e artista plástico Mário Alberto e o actor e estudioso entusiasta do teatro e do fado José Manuel Osório, fica-nos a saudade deles, mas também o 


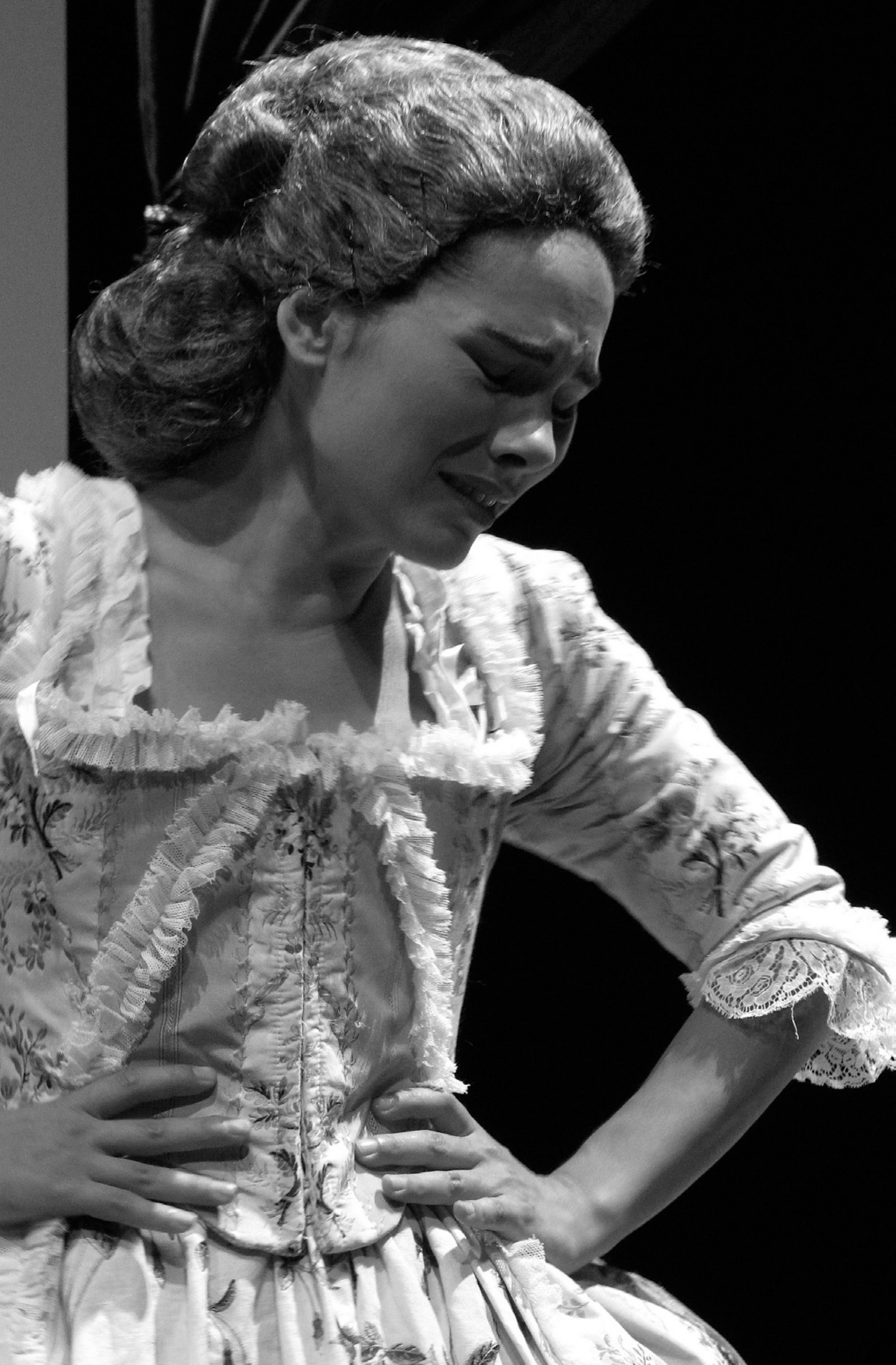


Amadeus (1979), de Peter Shaffer,

enc. Tim Carrol,

TNDMII, 2011

(Ivo Canelas),

fot. Isabel Rosa.

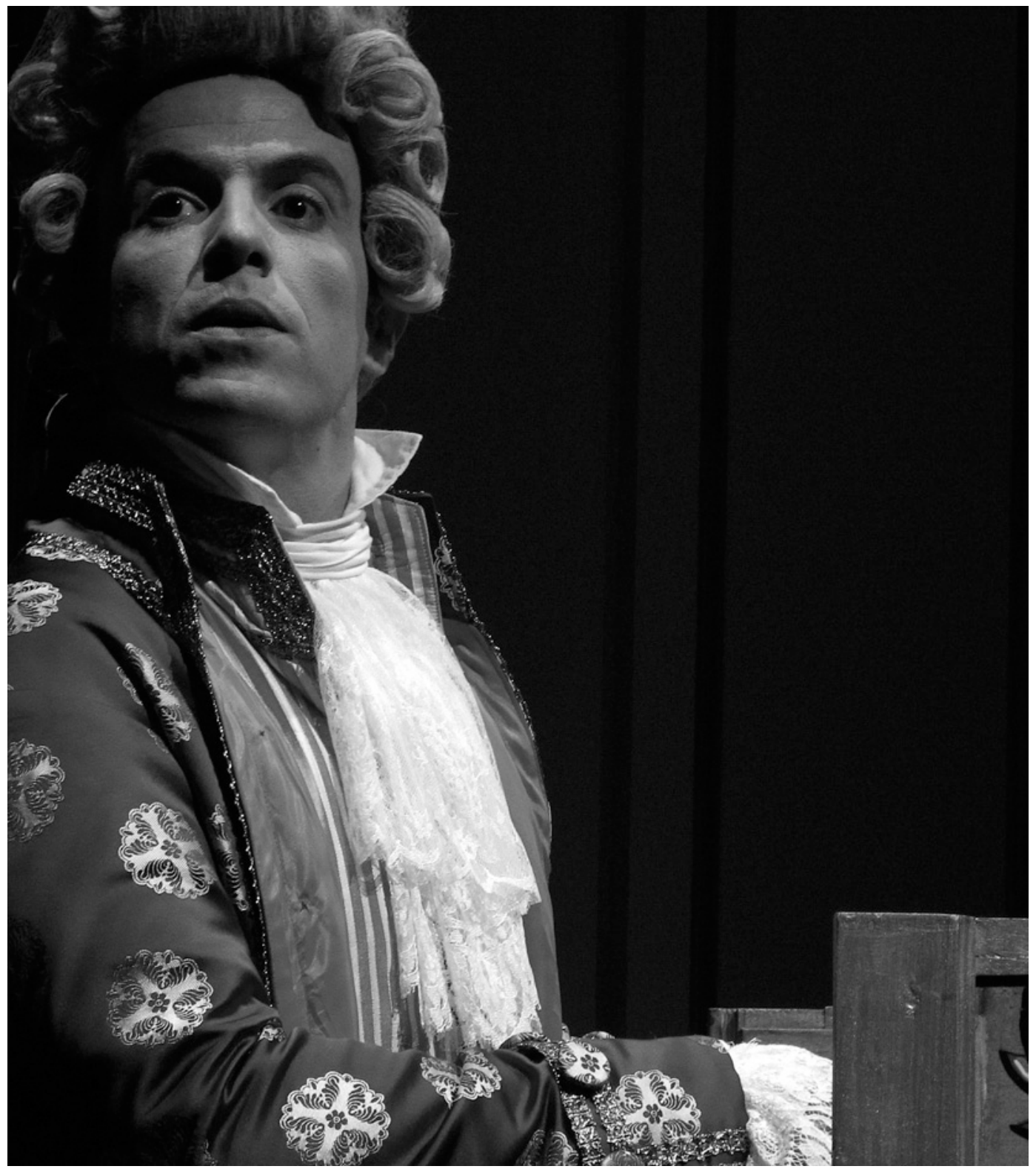

dever de reconsiderar a importância do teatro na nossa vida e o valor dos artistas que vão fazendo a nossa História e a respiração cultural do nosso quotidiano.

E, felizmente, é disso que nos fala João Pedro Vaz no "Portefólio" ao revelar como, no Minho em 2004, cinco presidentes de câmara (de Monção, Melgaço, Paredes de Coura, Valença e Vila Nova de Cerveira) resolveram lançar um projecto de teatro como é o d' As Comédias do Minho e que em 2007 se alargou ainda a uma tripla intervenção cultural: uma companhia de teatro, um projecto pedagógico (desenhado de raiz) e projectos comunitários envolvendo os grupos de teatro amador e as associações locais. Este é o modelo que serve de base à identidade d' As Comédias do Minho, demonstrado no fôlego artístico e no percurso excepcional que aqui se documentam em imagens.

Do trajecto mais longo de dois grandes homens de teatro se fala também neste número: nos "Estudos aplicados", o de Joaquim Benite - homem de invulgar competência e dinamismo, ex-crítico de teatro, encenador, criador do Grupo de Teatro de Campolide, actual director da Companhia de Teatro de Almada e notável director do Festival Internacional de Teatro de Almada -, e, na secção
"Na primeira pessoa", o de Fernando Gomes. É, pois, em discurso directo que nos chega a voz deste artista multifacetado, respondendo a questões pertinentes (e bem organizadas) que Teresa Faria e Rita Martins Ihe colocavam, mas que foi decerto fluindo ao ritmo de uma memória ardente e sequiosa de vida e de alegria. E é assim que, em amena conversa, este grande homem de teatro - diríamos de "todo o teatro possivel" - nos fala da sua infância, do seu trajecto pessoal, das histórias que viveu, das criações que assinou e do entusiasmo imenso que recolhe desta sua criatividade. Aliciante pelo que nos revela da sua personalidade, enternecedor pela sua emotividade à flor da pele, divertido na sua filosofia de aceitação dos outros, Fernando Gomes desfia as incontáveis experiências de vida e de arte com que foi enriquecendo a sua e a nossa vida. Como superlativa "crónica breve" de um tempo que ele ajudou em muito a fazer.

Nota: com a excepção do artigo do nosso colega brasileiro Arthur E.A Belloni, que escreve no português do Brasil, e da introdução ao "Portefólio" por parte de João Pedro Vaz, os restantes artigos deste número da Sinais de cena mantêm a grafia portuguesa anterior ao recente acordo ortográfico. 